\title{
DOS CUENTOS OLVIDADOS DE VICENTE RIVA PALACIO
}

\author{
$\mathbf{P} \mathbf{O} \mathbf{R}$
}

\section{U I S L E A L}

Dor razones que no podemos por ahora explicar, dos de los cinco "Cuentos del General" que don Vicente Riva Palacio publicó en Madrid en 1893 no fueron incluidos por su autor en el volumen que con ese título publicó en la Corte el año de su muerte (1896). Dichos cuentos, hasta hoy no recogidos en antología o colección alguna, son "Los azotes" y "Un buen negocio". Ambos aparecieron en la Ilustración Española y Americana, prestigiada revista madrileña, en 1893, el primero el 15 de enero y el segundo el 5 de febrero. Allí mismo encontramos otros tres cuentos de esta colección, los titulados "La horma de su zapato", "En una casa de empeños" y "La leyenda de un santo". ¿ Por qué -nos preguntamos- dejó el General los dos primeros, y no los otros tres, fuera de texto? Tal vez se deba - como ya apuntó Manuel Toussaint en el excelente "Prólogo" a su edición de estos cuentos- a que Riva Palacio murió antes de que su obra viera la luz pública, y el impresor no se atrevió a incluir relatos que no habián sido corregidos por el autor. Lo que nos parece también extraño es que el mismo Toussaint no los mencione, ni los haya incluido en su edición de 1929, como tampoco se añadieron a otra posterior (1952), aunque aquí no se trata de una edición crítica, sino de una mera reproducción de la de 1896 , y en la cual se incluyen hasta las ilustraciones originales. Por esta razón, nos parece, por lo tanto, justificado reproducir ambos cuentos al pie de estas notas, aunque el segundo nada tenga que ver con ellas. Esperamos que sean añadidos 
a la próxima edición que se publique de estos amenos y nunca olvidados Cuentos del General.

De los dos cuentos, el de más interés, por tratarse de un personaje histórico, es el primero. El origen de este episodio en la vida de Cortés, según parece, es la noticia que se encuentra en una crónica olvidada del siglo XVII. Bien sabido es que el General Riva Palacio era amante de Ieer viejos cronicones de la época colonial, de los cuales extraía los elementos para entretejer sus historias y novelas, lo mismo que las anécdotas que gustaba contar a sus amigos intimos. Su conocimiento de este período histórico lo demostró en su obra relativa a esa época, que forma parte de la colección México a través de los siglos, que él dirigió. De tema colonial mexicano son, además de sus novelas, sus cuentos "Las mulas de su excelencia", "La honras de Carlos V", "Ciento por uno", "La leyenda de un santo" y "El voto del soldado"; a los que hay que agregar "Los azotes", cuya fuente primitiva es, indirectamente, una pintura colonial.

Los temas que el General Riva Palacio utilizó para sus cuentos no son, por lo general, propios. ${ }^{1} \mathrm{El}$ que nos ocupa, según parece, era bien conocido y ha de haber andado en boca del pueblo desde la época colonial. El mismo autor menciona en el cuento una pintura representando este episodio cortesiano. De los cuadros sobre el tema, el más antiguo, aparentemente, es el mural que todavía se conserva en la porteria del convento franciscano de Ozumba, ${ }^{2}$ y que data del siglo xvII, según opinión de Kubler apoyada por Romero de Terreros (Ibid., p. 19). He aquí cómo describe este último crítico el mural de Ozumba: "De la misma época de la pintura de Cortés y los religiosos deben de ser las que se ejecutaron en los angostos lienzos de pared que hay a cada lado de la arquería. En el de la izquierda, hoy muy maltratado, se representó aquel acto de humildad de Hernán Cortés, cuando, para edificación de los indios, se dejó azotar públicamente, por haber llegado tarde a misa. El conquistador, de rodillas, con los mismos gregüescos a rayas que viste en la pintura mayor, pero desnudo de la cintura para arriba, recibe sobre sus espaldas los latigazos que le propina un fraile y que parecen más simbólicos que efectivos, en presencia de cuatro impávidos caciques.

1 Véase nuestro estudio Vicente Riva Palacio, cuentista, en la "Revista Iberoamericana", xxIr, núm. 44, julio-diciembre, 1957, pp. 301-309.

2 Ver Manuel Romero de Terreros, El convento franciscano de Ozumba y las pinturas de su porteria, "Anales del Instituto de Investigaciones Estéticas", vI, núm. 24, 1956, pp. 9-21. 
DOI: http://dx.doi.org/10.22201/iie.18703062e.1958.27.653

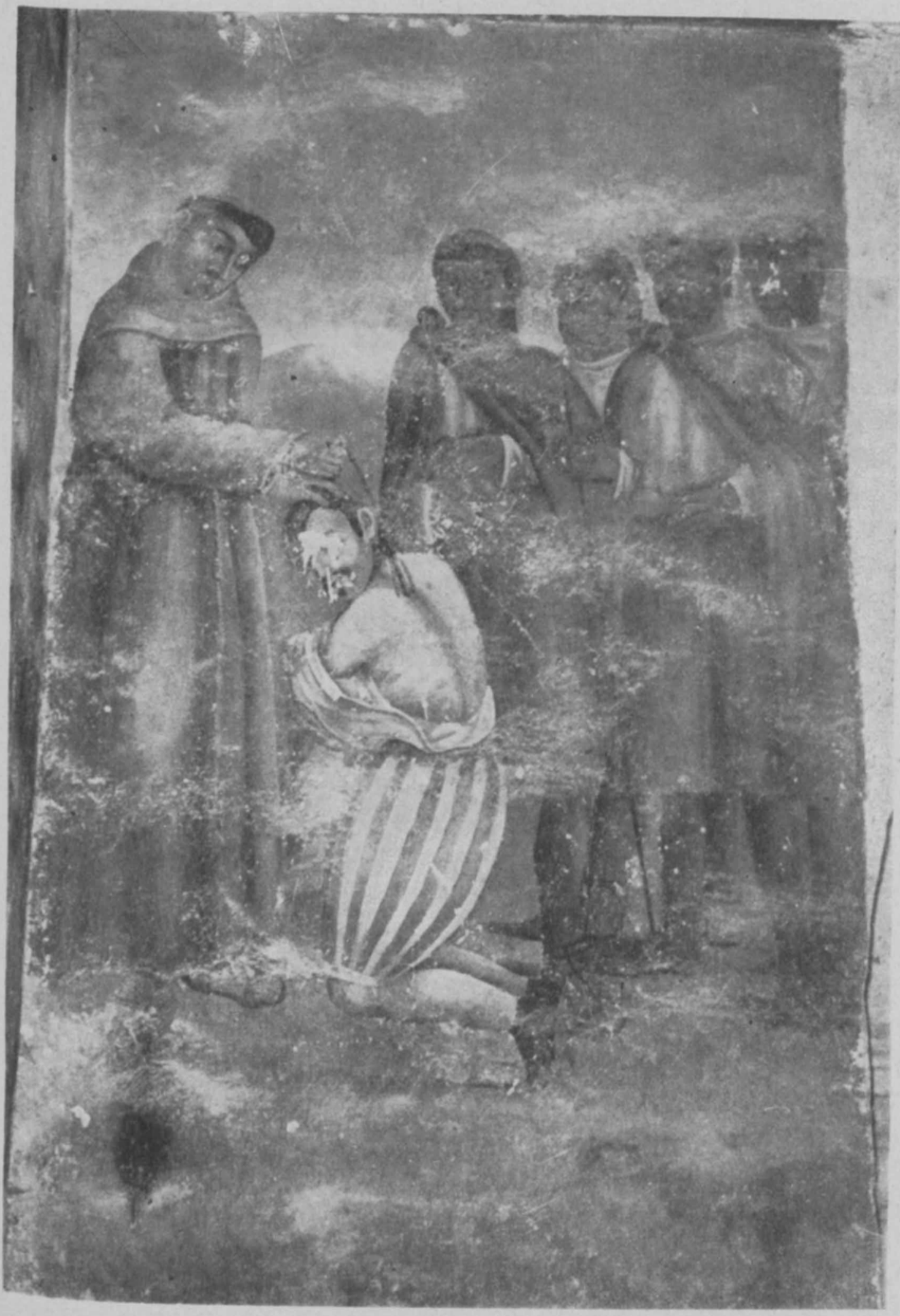


DOI: http://dx.doi.org/10.22201/iie.18703062e.1958.27.653 
(Ibid.)" Otro cuadro sobre este mismo asunto es el que menciona Riva Palacio en su cuento: " $\mathrm{Ni}$ la historia ni la tradición han conservado el número de azotes que recibió el conquistador; pero tal resonancia tuvo el hecho, que todavía a principios de este siglo, en una capilla que había en México, que llevaba el nombre de los talabarteros, y que fue destruída por un incendio, existia un gran cuadro, en el que estaba representado Cortés de rodillas, con las espaldas desnudas y la cabeza inclinada, recibiendo los azotes que le aplicaba un misionero franciscano." Nótese que Riva Palacio no dice que el cuadro existe. Por lo tanto, la noticia de su existencia debe de haber sido sacada por el General de alguna historia o crónica. Y en verdad, en la curiosa obra Noticias de México de Franciscisco Sedano, ${ }^{3}$ publicada por don Joaquín Garcia Icazbalceta en 1880, hallamos, bajo el artículo "Talabarteros", la siguiente peregrina nota: "Ia capilla llamada de los talabarteros, dedicada a la Santa Cruz, es sexavada, de seis ángulos, cada una de seis varas, y 36 varas de circunferencia. Está alta, respecto a la planicie de la tierra, y para entrar en ella se suben siete escalones, la puerta mira al Sur, y la parte del Norte tiene una corta sacristía, y tiene un cimborrio. El altar está a la parte del Norte, delante de la sacristía que queda detrás, y está dedicado a la Santa Cruz, que ocupa el lugar principal, y arriba un lienzo de Nuestra Señora de Guadalupe. Un ángulo ocupa el altar, otro la puerta, y los cuatro restantes están ocupados con lienzos, cuyas pinturas representan lo siguiente: La primera misa que se dijo en esta tierra, la aparición de Nuestra Señora de Guadalupe al Sr. Zumárraga, el primer bautismo que se celebró solemnemente en esta Nueva España, y cuando Cortés se hizo azotar delante de los indios, fingiendo que era por haberse tardado en ir a oir misa."

Como dato curioso para la historia de la pintura en México copiamos también lo que agregó el presbítero Vicente de P. Andrade, a quien pertenecen las notas del libro de Sedano: "Estos cuadros se conservan felizmente en la iglesia parroquial de Santa Cruz Acatlán. El primero está en el presbiterio, el segundo en el coro, el tercero también en el presbiterio y el cuarto en el cuerpo de.la iglesia (t. II, pp. 159-61)." Lo anterior se escribía antes de 1880. Para 1884, según noticias de García Cubas, ya solamente había tres de ellos: "Y la parroquia Santa Cruz

3 Según Beristáin, Sedano, mercader de libros, nació en la ciudad de México, y allí murió a los 70 años de edad, en 1812, dejándole todos sus manuscritos. 
Acatlan, iglesia de las más antiguas $y$ en la que existen tres cuadros históricos." 4

No sabemos si estos cuadros todavía existen, y aparentemente el mismo Riva Palacio no lo sabía, ya que no los menciona. Tampoco sabemos el año del incendio de la iglesia de los Talabarteros, que no figura en las listas de iglesias más conocidas de la ciudad de México. ${ }^{5}$ Pero basta con el mural de Ozumba para estar seguros de que el episodio de los azotes recibidos por Cortés, como dice el general, tuvo gran resonancia. He aquí el texto de este interesante cuento, hasta hoy injustamente olvidado.

\section{LOS AZOTES}

Después de largo y sangriento sitio ocupó Hernán Cortés la capital del Imperio de Moctehuzuma; pero quedó la ciudad en tan lastimoso estado, que el conquistador, con su ejército, tuvo que acampar durante algún tiempo en la cercana villa de Coyoacán, porque en México ni lugar pudo encontrarse para el alojamiento de los soldados.

Pocos meses después, los trabajos de la reedificación habían avanzado tanto, que ya el conquistador pudo trasladarse allí, y eran tan activos, que dice el padre Motolinia, en su Historia de los indios de la Nueva España, que "en la edificación de la gran ciudad de México en los primeros años, andaba más gente que en la edificación de Jerusalén; porque era tanta la gente que andaba en las obras, que apenas podria hombre romper por algunas calles y calzadas, aunque son muy anchas".

$Y$ ya entonces el conquistador de México no era Hernán Cortés a secas, sino que se llamaba el muy Magnífico Señor Hernán Cortés, gobernador y capitán general de la Nueva España; que el don aún no lo usaba, porque hasta algunos años después no se lo concedió el Emperador.

Por aquellos días aconteció, según refiere la tradición, que el Gobernador y Capitán General publicó un bando exigiendo la puntual asistencia de todos los vecinos a las misas que celebraban los padres franciscanos, primeros religiosos que a predicar el cristianismo llegado habian a la Nueva España.

4 Antonio García Cubas, Cuadro geográfico, estadistico, descriptivo e histórico de los Estados Unidos Mexicanos. México, 1884, p. 278.

5 En su obra México en 1810 (México: Editorial Stylo, 1943), don Luis González Obregón menciona esta capilla (pp. 24-25) como todavía existente en ese año, aunque sitn citar ninguna autoridad para verificar el hecho. 
La morosidad de los soldados para asistir al Santo Sacrificio, y la indiferencia o poca costumbre que de ello tenían los indios, hacía que muchos llegasen a la iglesia ya pasado el evangelio, o cuando el sacerdote pronunciaba las últimas oraciones, causando con eso escándalo entre aquel rebaño de ovejas recién convertidas al cristianismo.

Quejáronse a Cortés los celosos misioneros, y de aqui nació la disposición del conquistador, para que todos asistiesen puntuales a la misa, so pena de que cualquiera que llegase después del evangelio, recibiera de mano de los religiosos quince o veinte azotes, desnudo de la cintura para arriba si era hombre, o sobre las ropas, si era mujer.

Comenzaron a murmurar de tal disposición conquistadores y conquistados, diciendo que no se llevaría eso de los azotes a puro y debido eiecto, cuando la pena recayese, bien en capitanes como Pedro de Alvarado, Gonzalo de Sandoval, Cristóbal de Olid y Diego de Tapia, por las atenciones con que les trataba Cortés, o en los grandes señores y caciques de la tierra, de quien podia temerse que, ofendidos, provocaran una nueva y más terrible insurrección.

No podía ignorar Hernán Cortés aquellas murmuraciones, pero jamás dio a comprender que las sabia, y el rumor seguía circulando y tomando creces, sin que nadie cuidase de contradecirlo.

Un dia, domingo por cierto, celébrase la misa en el provisional templo de los franciscanos, y ya pasado había el evangelio, cuando Cortés, sin acompañamiento de ninguna clase, apareció a la puerta de la iglesia, atravesó la nave cruzando entre los asistentes y fue a arrodillarse devotamente en el presbiterio.

Los fieles alli reunidos, si no lo dijeron, pensaron indudablemente que el conquistador había merecido la misma pena por él impuesta, llegando a misa después de haberse leido el evangelio; aunque ninguno, ni remotamente, se figuró que aquello podría tener consecuencias.

Pero con gran asombro, al terminar la misa, vieron a dos franciscanos acercarse a Cortés, y a éste, levantarse humildemente del lugar que ocupaba y de rodillas delante del altar, despojarse de su ropa, prestar las espaldas desnudas a los misioneros.

$\mathrm{Ni}$ la historia ni la tradición han conservado el número de azotes que recibió el conquistador; pero tal resonancia tuvo el hecho, que todavía a principios de este siglo, en una capilla que había en México, que llevaba el nombre de los talabarteros, y que fue destruida por un incendio, existía un gran cuadro, en el que estaba representado Cortés de rodi- 
llas, con las espaldas desnudas y la cabeza inclinada, recibiendo los azotes que le aplicaba un misionero franciscano.

Inútil es decir que la lección no pudo ser más provechosa. Si Cortés hizo aquello de acuerdo con los franciscanos y para dar un ejemplo de humildad y de respeto a la ley, o si realmente sin previo acuerdo los franciscanos tuvieron el valor de aplicar el bando, y él la resignación de someterse; con toda seguridad no se puede decir, y en eso cada uno pensará lo que mejor le parezca.

\section{UN BUEN NEGOCIO}

Pocas veces el Lafayette, vapor de la Compañía Trasatlántica francesa, había sufrido, al cruzar el océano con rumbo a América, un temporal más largo y más espantoso. Las olas, semejando montañas negras, pasaban en vertiginosa carrera, chocando contra el casco del buque, levantándose hasta la cubierta, precipitándose por las escaleras y saliendo por los imbornales, en los que se producía un ruido pavoroso y un hervor siniestro. El huracán cruzaba por la arboladura, gimiendo, silbando, remedando algunas veces el ruido de un carro de bronce sobre una bóveda de acero; otras, el aullido de un lobo; otras, el agudo silbar de la serpiente. Densas nubes de color indefinible se arremolinaban en el cielo, tan bajas, que casi envolvían el cataviento de la embarcación.

Bailaba el vapor, perdido en aquella inmensidad, como una hoja de árbol arrebatada por un torbellino. Los marineros, cubiertos con sus vestidos amarillentos de lona embreada y empapados por la lluvia, corrían precipitados de un lado a otro. Todas las escotillas y todas las puertas estaban cerradas y clavadas; los pasajeros, encerrados, unos se agrupaban en el salón, y otros se habían retirado a sus camarotes; pero todos llenos de pavor, oían cada crujido del casco como la última señal de la catástrofe. Las mujeres rezaban, los hombres estaban silenciosos.

*

Entre los pasajeros que el vapor Lafayette conducía a Veracruz, iba don Rosendo de Figueroa que, por nacimiento, era mexicano, pero por su aspecto le hubiera tomado cualquiera por uno de esos ingleses que han enriquecido en los climas tropicales, perdiendo el color del rostro de los 
hijos de Albión para adquirir el moreno y tostado cutis de los hombres que nacen en aquellas ardientes regiones.

Don Rosendo era un hombre capaz de hacer un buen negocio con el primero que encontraba en la calle, en la iglesia o en un compartimiento de ferrocarril. Tenía el don de ganar dinero, $y$, en verdad, también el de gastarlo, porque era espléndido y franco como un nabab, y sus repetidos viajes a Europa le habían hecho un hombre de buen gusto.

Era de regular estatura, moreno, delgado; contaría cincuenta años; su pelo comenzaba a estar canoso, pero sus ojos estaban brillantes como los de un hombre de treinta, y había en su mirada algo así de la rapidez de los golpes de los buenos esgrimidores de florete.

Don Rosendo no era valiente, y además hacía gala de ser observante en religión y de ser hombre de arraigadas creencias; así es que, cuando arreció la tormenta tuvo mucho miedo y comenzó a rezar.

Llegó un momento en que el hombre se creyó perdido, y recurrió, como en semejante caso hacen muchos, a las promesas, cosa más natural en él por ser hombre tan acostumbrado a ver un negocio en todos los acontecimientos de la vida.

-i Madre Santísima de Guadalupe! -exclamó, porque todos los mexicanos son muy devotos de la Virgen de Guadalupe- si me salvas de este trance y llego con felicidad a mi casa, te prometo mandarte decir dos mil misas.

Realmente el negocio no era malo; la vida de don Rosendo, con todas sus consecuencias, no salia cara por dos mil misas, aun cuando más barato hubiera salido París en aquello que dijo Enrique IV (según dicen), que "París bien vale una misa". Pero las mil novecientas noventa y nueve de más las daba con mucho gusto en aquellos instantes don Rosendo.

Aunque con algún retraso, el Lafayette llegó felizmente a Veracruz; desembarcó don Rosendo, dando gracias a Dios por haberlo salvado. Tomó el ferrocarril; llegó a México y volvió a embarcarse otra vez, no en el Atlántico, sino en el revuelto mar de sus negocios.

Pasaban los días y los meses y don Rosendo no cumplía su promesa, pero tampoco la olvidaba, y era un remordimiento sordo, que le causaba algunos desvelos.

Como era un solterón recalcitrante, llegaba una hora en la noche, antes de dormirse, en que se encontraba solo, pensando en sus negocios, y siempre, en medio de aquella interminable serie de combinaciones, aparecía el recuerdo de la promesa como uno de esos pretendientes pertina- 
ces que en todas partes se les presentan a los ministros, no más para decirles: "iAquí estoy !"

Don Rosendo desechaba aquello como un mal pensamiento, diciendo siempre para calmar su conciencia: "Mañana en cuanto me levante, arreglo este negocio."

Por fin, un día aquel negocio tuvo que arreglarse. El comerciante llamó a un clérigo muy su conocido, y le dijo:

-Oiga usted, Padre; va usted a decir cinco misas a la Virgen de Guadalupe, y por cada una de ellas le voy a dar cien duros.

El pobre clérigo estuvo a punto de desmayarse; porque es de advertir que alli la limosna por cada misa cs generalmente, por lo menos, un duro; pero aún no se había repuesto de su emoción, cuando don Rosendo agregó :

- Pero me va usted a firmar un recibito en que diga usted que ha recibido dos mil duros por haber dicho dos mil misas.

La tentación era grande; el clérigo no debía ser muy escrupuloso, y el recibo se firmó en papel que llevaba todos los requisitos necesarios y exigidos por la ley para esta clase de documentos.

Aquel día don Rosendo estuvo más alegre que de costumbre, y decía a sus amigos, frotándose las manos, a la hora de almorzar:

-Ahora sí estoy muy contento; me he quitado de encima un compromiso viejo, ganando mil quinientos pesos en menos de un cuarto de hora. Este sí que es un buen negocio.

Pasaron así dos semanas, y un día don Rosendo recibió una carta del clérigo, diciéndole que los médicos le habian desahuciado, que estaba muy grave, que no había podido decir las misas y se había gastado doscientos duros; pero que en descargo de su conciencia le devolvía trescientos en billetes de banco, y que le perdonara los otros.

Don Rosendo contó los billetes; eran trescientos pesos más de ganancia, y tenía el recibo de las dos mil misas, y cuenta saldada.

Tomó la pluma y contestó :

-Recibí el dinero, y el resto se lo perdono para aquí y en presencia de Dios. 